\title{
Risk factor analysis for postoperative acute respiratory distress syndrome and early mortality after pneumonectomy: The predictive value of preoperative lung perfusion distribution
}

\author{
Joon Bum Kim, MD, ${ }^{\text {a }}$ Sei Won Lee, MD, ${ }^{\mathrm{b}}$ Seung-Il Park, MD, ${ }^{\mathrm{a}}$ Yong Hee Kim, MD, ${ }^{\mathrm{a}}$ and \\ Dong Kwan Kim, MD
}

\begin{abstract}
Objectives: This study aims to establish the preoperative risk factors in the development of acute respiratory distress syndrome (ARDS) and early mortality after pneumonectomy for lung cancer and to examine the influence of reduced pulmonary perfusion on outcomes.
\end{abstract}

\begin{abstract}
Methods: Between 1994 and 2009, of 425 patients who underwent simple pneumonectomy for primary lung cancer, 164 who were preoperatively evaluated with lung perfusion scanning formed the population of this study.

Results: Of $30(18.3 \%)$ patients who had major pulmonary complications, $17(10.4 \%)$ progressed to ARDS, 15 of whom subsequently died. On multivariable logistic regression analyses, lower predicted postoperative forced expiratory volume in 1 second (ppo-FEV ${ }_{1}$; relative risk of $0.93[P=.020]$ for ARDS and $0.94[P=.027]$ for mortality) and greater perfusion fraction of resected lung (relative risk of $1.10[P=.003]$ for ARDS and 1.09 $[P=.002]$ for mortality) were found to be independent factors associated with ARDS and early mortality. With a cut-off value of $35 \%$ for perfusion fraction of resected lung, patients with a perfusion fraction of greater than $35 \%$ had a greater incidence of ARDS $(17.3 \%$ vs $3.3 \%, P=.005)$ and early mortality $(19.8 \%$ vs $6.0 \%$, $P=.010)$ than those with a perfusion fraction of $35 \%$ or less.
\end{abstract}

Conclusions: Patients with a low ppo-FEV ${ }_{1}$, a high perfusion fraction of resected lung, or both had a higher incidence of ARDS and early mortality after pneumonectomy. Therefore, although the ppo-FEV ${ }_{1}$ appears to be within an acceptable limit for pneumonectomy, much attention should be given to patients with a high perfusion fraction of resected lung. (J Thorac Cardiovasc Surg 2010;140:26-31)

Patients undergoing pneumonectomy are at significant risk of postoperative pulmonary complications, which constitute the leading cause of operative mortality. In particular, postpneumonectomy acute respiratory distress syndrome (ARDS) is associated with an extremely high mortality rate. ${ }^{1}$

Although most of the former studies focused on pulmonary function parameters in the prediction of postoperative pulmonary complications, ${ }^{2-6}$ several studies evaluated the influence of hemodynamic parameters on the postoperative outcomes after lung resection. ${ }^{7-10}$ The latter studies showed that high pulmonary vascular resistance or a lower perfusion fraction of nonresected lung were correlated with poor gas exchange capacity. ${ }^{9,10}$ However, these findings have not yet been supported by clinical analysis in that the influence of perfusion reduction after pneumonectomy on the development of pulmonary complications is not well investigated.

\footnotetext{
From the Department of Thoracic and Cardiovascular Surgery, ${ }^{\mathrm{a}}$ Asan Medical Center, University of Ulsan College of Medicine, Seoul, Korea; and the Department of Internal Medicine, ${ }^{\mathrm{b}}$ Armed Forces Capital Hospital, Seongnam, Korea.

Disclosures: None.

Received for publication May 14, 2009; revisions received Sept 27, 2009; accepted for publication Nov 8, 2009; available ahead of print Feb 4, 2010.

Address for reprints: Seung-Il Park, MD, Department of Thoracic and Cardiovascular Surgery, Asan Medical Center, University of Ulsan College of Medicine, 388-1 Pungnap 2-dong Songpa-gu, Seoul 138-736, Korea (E-mail: sipark@amc.seoul.kr). $0022-5223 / \$ 36.00$

Copyright (c) 2010 by The American Association for Thoracic Surgery doi:10.1016/j.jtcvs.2009.11.021
}

We therefore performed multivariable risk factor analyses to determine factors associated with postoperative ARDS and early mortality and to examine the influence of reduced pulmonary perfusion on the outcomes after pneumonectomy for lung cancer.

\section{MATERIALS AND METHODS}

\section{Patient Selection and Preoperative Evaluation}

We reviewed all the cases who underwent pneumonectomy for primary lung cancer from January 1994 to April 2009 in Asan Medical Center, Seoul, Korea.

All patients were assessed by the same surgical team, and the preoperative study was standardized. Preoperative pulmonary function was assessed by using arterial blood gas and spirometric analysis. In any patients judged to have limited lung function, a ventilation and perfusion scan was performed to predict residual postoperative pulmonary function. Predicted postoperative forced expiratory volume in 1 second (ppo-FEV ${ }_{1}$ ) was calculated based on the preoperative forced expiratory volume in 1 second $\left(\mathrm{FEV}_{1}\right)$ and the pulmonary perfusion scan as follows:

$$
\begin{aligned}
& \text { ppo-FEV }{ }_{1}=\text { Preoperative } \mathrm{FEV}_{1} \times(1-\text { Fraction of total perfusion } \\
& \text { for the resected lung }) .
\end{aligned}
$$

A cardiopulmonary exercise test was performed in cases in which ppo$\mathrm{FEV}_{1}$ was less than $40 \%$ of the reference value. The test involved treadmill exercise with stepwise increases in workload (speed) until symptom limitation occurs. For patients with maximal oxygen consumption of less than 15 $\mathrm{mL} \cdot \mathrm{kg}^{-1} \cdot \mathrm{min}^{-1}$, palliative therapy was performed instead of surgical intervention. All patients underwent bone scanning for metastasis work-up, and additional evaluations (eg, brain computed tomographic scanning or 


\section{Abbreviations and Acronyms \\ ARDS = acute respiratory distress syndrome \\ $\mathrm{BPF}=$ bronchopleural fistula \\ $\mathrm{CI}=$ confidence interval \\ $\mathrm{FEV}_{1}=$ forced expiratory volume in 1 second \\ ICU $=$ intensive care unit \\ ppo-FEV $V_{1}=$ predicted postoperative forced expiratory volume in 1 second \\ $\mathrm{RR} \quad=$ relative risk}

biopsy of suspicious metastatic lesions) were performed in cases of clinically suspected metastasis. Preoperative routine electrocardiographic analysis was conducted in all patients. In patients with a history or risk factors of ischemic heart disease, a cardiologic evaluation was performed and usually supplemented by cardiologic consultation with a stress test and echocardiographic analysis.

A total of 469 patients underwent pneumonectomy for primary lung cancer during the study period. Of those, patients subjected to procedures other than simple pneumonectomy, such as extrapleural pneumonectomy $(\mathrm{n}=1)$, sleeve pneumonectomy $(n=4)$, reoperation $(n=24)$, or pneumonectomy involving combined resection of the chest wall, mediastinal structures (eg, heart and great vessels), or diaphragm $(\mathrm{n}=15)$, were excluded.

Of the 425 patients who underwent simple pneumonectomy, we identified 164 patients who were evaluated with lung perfusion scanning preoperatively, and these patients formed the population of the present study. The indications for lung perfusion scanning were significant airflow obstruction on spirometric analysis $\left(\mathrm{FEV}_{1}<65 \%\right.$ of predicted value, $\mathrm{FEV}_{1}$ $<2 \mathrm{~L} / \mathrm{min}$, or $\mathrm{FEV}_{1}$ /forced vital capacity ratio $<0.7$ ) in 126 patients, poor functional capacity without the evidence of airflow obstruction in 28 patients, and poor diffusion capacity of carbon monoxide $(<65 \%$ of predicted value) in 4 patients. Six patients underwent lung perfusion scanning without a remarkable indication.

Consequently, the patients included in the current study showed higherrisk features than those who underwent simple pneumonectomy without lung perfusion scanning, as evidenced by older age, more frequent smoking history, and poorer pulmonary function test results (Table 1).

Patients were staged postoperatively according to the TNM staging system. Postopoperative staging was as follows: stage Ia $(n=5[3.0 \%])$, stage $\mathrm{Ib}(\mathrm{n}=31[18.9 \%])$, stage IIa $(\mathrm{n}=2[1.2 \%])$, stage IIb $(\mathrm{n}=54[32.9 \%])$, stage IIIa $(n=62[37.8 \%])$, stage IIIb $(n=9[5.5 \%])$, and stage IV $(n=1$ $[0.6 \%])$. The histologic distribution of the tumors was as follows: squamous cell carcinoma $(n=126[76.8 \%])$, adenocarcinoma $(n=28[17.1 \%])$, adenosquamous cell carcinoma $(\mathrm{n}=4[2.4 \%])$, small cell carcinoma $(\mathrm{n}=2[1.2 \%])$, and "other" $(\mathrm{n}=4[2.4 \%])$.

This study was approved by our institutional ethics committee/institutional review board, and individual consent for the study was waived.

\section{Surgical Treatment}

All patients were operated on by the same surgical team using a standard posterolateral thoracotomy, sparing the serratus anterior muscle with routine cutting of the sixth rib. Bronchial closure was performed with staplers (Ethicon Endo-Surgery, Inc, Cincinnati, Ohio; Autosuture USSC, Norwalk, Conn). The bronchial stump was covered with an autologous mediastinal fat pad or intercostal muscle pedicle. After the lung specimen was acquired, frozen pathologic examination was performed to determine the adequacy of the resection margin. If the resection margin was positive for malignancy, additional resection was performed until negative confirmation of malignancy. In all cases mediastinal lymph node dissection was performed for exact pathologic staging. Once the chest was closed, the postpneumonec- tomy space was managed with stepwise evacuation of air from the operated hemithorax until the sensation of resistance is obtained. This procedure was designed to return the mediastinum to the midline and usually required about $1 \mathrm{~L}$ of air evacuation.

\section{Perioperative Management}

All patients started an active program of chest physiotherapy, including deep breathing exercises and incentive spirometry, during a preoperative period of 3 to 7 days. For the management of postoperative pain, epidural patient-controlled anesthesia was routinely used.

Patients were extubated in the operating room $(89.6 \%)$ or immediately after transfer to the intensive care unit (ICU; 10.4\%). Intravenous fluid administration was restricted to a minimum, and blood transfusion was limited to patients who had a hemoglobin level of $8.0 \mathrm{~g} / \mathrm{dL}$ or less during the perioperative period.

Postoperatively, all patients remained at least 1 day in the ICU. When discharged from the ICU, patients were managed in the thoracic ward. All patients received postoperative training in chest physiotherapy.

\section{Postoperative Complications}

Postoperative complications and early mortality were defined as those occurring within 30 days after the procedure or before hospital discharge. To analyze pulmonary complications, we have defined pulmonary complications as follows. The diagnosis of pneumonia was considered when patients had a lung infiltrate and purulent sputum with documented presence of microorganisms in the sputum culture. Postpneumonectomy pulmonary edema was defined as pulmonary edema without evidence of pneumonia, heart failure, and pulmonary embolism after appropriate diagnostic process. Bronchopleural fistula (BPF) was defined as abnormal development of fistula between the bronchial stump and the interpleural space. ARDS was defined as acute onset of arterial hypoxemia refractory to oxygen therapy (defined as a $\mathrm{PaO}_{2} /$ fraction of inspired oxygen ratio of $\leq 200$ ) associated with diffuse infiltrates on chest radiographic analysis without evidence of myocardial infarction or heart failure. For the differential diagnosis of ARDS, such patients were evaluated with electrocardiographic analysis, cardiac enzyme measurement, and echocardiographic analysis.

\section{Data Collection and Analysis}

Categoric variables were presented as frequencies and percentages and were compared by using the $\chi^{2}$ or Fisher's exact tests. Continuous variables were expressed as means \pm standard deviations and were compared by using the Student's unpaired $t$ test.

Univariable and multivariable risk factor analyses were performed by using the logistic regression method. Variables with a $P$ value of .20 or less in univariable analyses were candidates for the multivariable models. Multivariable analyses involved a backward elimination technique, and only variables with a $P$ value of less than .10 were used in the final model. Results were expressed as the relative risk (RR) with 95\% confidence interval (CI). Because the perfusion fraction of resected lung is directly related to ppo- $\mathrm{FEV}_{1}$, separate multivariable analyses were performed, one including perfusion fraction without $\mathrm{ppo}-\mathrm{FEV}_{1}$ and one including ppo- $-\mathrm{FEV}_{1}$ without perfusion fraction to prevent the problem of interaction between the variables.

The predictive value of resected lung perfusion fraction for postoperative ARDS was evaluated by using the area under the receiver operating characteristic curve with its $95 \% \mathrm{CI}$. The optimal cut-off corresponded to the value with the greatest accuracy.

All reported $P$ values are 2-sided. Statistical analyses were performed with SPSS 14.0 for Windows software (SPSS, Inc, Chicago, Ill).

\section{RESULTS}

Major pulmonary complications occurred in 30 patients (Table 2). Fourteen of 16 patients with pneumonia and all 3 
TABLE 1. Preoperative characteristics of patients who underwent simple pneumonectomy for lung cancer

\begin{tabular}{|c|c|c|c|}
\hline & $\begin{array}{l}\text { Patients without lung perfusion } \\
\text { scan evaluation }(n=261)\end{array}$ & $\begin{array}{l}\text { Patients with lung perfusion } \\
\text { scan evaluation }(n=164)\end{array}$ & $P$ value \\
\hline Age (y) & $60.0 \pm 10.2$ & $63.5 \pm 9.3$ & $.001 *$ \\
\hline Female sex, no. $(\%)$ & $41(15.7)$ & $15(9.1)$ & .052 \\
\hline Diabetes mellitus, no. (\%) & $34(13.0)$ & $20(12.2)$ & .802 \\
\hline Smoking history, no. $(\%)$ & $213(81.6)$ & $148(90.2)$ & $.015^{*}$ \\
\hline \multicolumn{4}{|l|}{ Preoperative pulmonary function } \\
\hline FVC (L) & $3.5 \pm 0.7$ & $3.2 \pm 0.7$ & $<.001 *$ \\
\hline FVC ( $\%$ predicted $)$ & $91.9 \pm 13.3$ & $83.7 \pm 16.1$ & $<.001 *$ \\
\hline $\mathrm{FEV}_{1}(\mathrm{~L})$ & $2.5 \pm 0.5$ & $2.1 \pm 0.5$ & $<.001 *$ \\
\hline $\mathrm{FEV}_{1}(\%$ predicted $)$ & $91.7 \pm 16.2$ & $77.5 \pm 16.5$ & $<.001 *$ \\
\hline $\operatorname{DLCO}\left(\mathrm{mL} \cdot \min ^{-1} \cdot \mathrm{mm} \mathrm{Hg}^{-1}\right)$ & $18.7 \pm 4.5$ & $16.4 \pm 4.0$ & $<.001 *$ \\
\hline DLCO $(\%$ predicted $)$ & $97.4 \pm 19.1$ & $88.1 \pm 20.2$ & $<.001 *$ \\
\hline $\mathrm{FEV}_{1} / \mathrm{FVC}(\%)$ & $73.2 \pm 9.1$ & $66.6 \pm 10.5$ & $<.001 *$ \\
\hline $\begin{array}{l}\text { Perfusion fraction of resected lung } \\
\quad(\%)\end{array}$ & NA & $32.4 \pm 12.1$ & NA \\
\hline ppo-FEV 1 (L) & NA & $1.4 \pm 0.4$ & NA \\
\hline ppo-FEV 1 (\% predicted $)$ & NA & $53.5 \pm 11.6$ & NA \\
\hline Neoadjuvant therapy, no. $(\%)$ & $22(8.4)$ & $11(6.7)$ & .518 \\
\hline Chemotherapy only & 16 & 3 & \\
\hline Radiotherapy only & 0 & 1 & \\
\hline Concurrent chemoradiotherapy & 6 & 7 & \\
\hline Right pneumonectomy, no. $(\%)$ & $108(41.4)$ & $61(37.2)$ & .340 \\
\hline
\end{tabular}

$F V C$, Forced vital capacity; $F E V_{l}$, forced expiratory volume in 1 second; $D L C O$, diffusion capacity of carbon monoxide; $p p o-F E V_{l}$, predicted postoperative forced expiratory volume in 1 second; $N A$, not applicable. ${ }^{*} P<.05$.

patients with postpneumonectomy pulmonary edema progressed to ARDS. Of the 17 patients with ARDS, 15 $(88.2 \%)$ died subsequently, despite aggressive medical therapy. Bronchial reclosure was performed in all patients with BPF $(n=7)$, and 4 of them died of aspiration pneumonia.

The early mortality rate was $12.8 \%(n=21)$. Causes of early mortality were surgical bleeding in 1 patient, ARDS in 15 patients, BPF followed by aspiration pneumonia in 4 patients, and empyema without BPF in 1 patient.

Univariable analyses to identify the risk factors for postoperative ARDS and early mortality showed that lower ppo-FEV ${ }_{1}$, higher perfusion fraction of resected lung, and right (vs left) pneumonectomy were significantly correlated with both events (Table 3). Multivariable analyses revealed that lower ppo-FEV $\mathrm{F}_{1}$ and higher perfusion fraction of resected lung were independent factors associated with ARDS and early mortality (Table 4). Right pneumonectomy

TABLE 2. Postoperative pulmonary complications

\begin{tabular}{lccc}
\hline \multicolumn{1}{c}{ Complication } & No. (\%) & ARDS, no. (\%) & Mortality, no. (\%) \\
\hline Pneumonia & $16(9.8)$ & $14(8.3)$ & $12(7.3)$ \\
PPE & $3(1.8)$ & $3(1.8)$ & $3(1.8)$ \\
BPF & $7(4.3)$ & - & $4(2.4)$ \\
Empyema without BPF & $3(1.8)$ & - & $1(0.6)$ \\
Total & $30(18.3)$ & $17(10.4)$ & $20(12.2)$ \\
\hline$A R D S$, Acute respiratory distress syndrome; $P P E$, postpneumonectomy pulmonary \\
edema; $B P F$, bronchopleural fistula.
\end{tabular}

showed an RR of 2.33 for ARDS (95\% CI, 0.66-8.17; $P=.187)$ and an RR of 2.06 for early mortality (95\% CI, $0.68-6.27 ; P=0.204$ ) in the prefinal multivariable model, and therefore it did not enter the final model.

When the predictive value of resected lung perfusion fraction for postoperative ARDS was assessed by using the receiver operating characteristic curve, the curve yielded an area under the curve of 0.723 (95\% CI, 0.61-0.84; $P=.003)$. The greatest accuracy for the prediction of ARDS was obtained at the cut-off value of $35.9 \%$, with $82.4 \%$ sensitivity and $54.4 \%$ specificity.

With a cut-off value of $35 \%$ for perfusion fraction of resected lung, patients with a perfusion fraction level of greater than $35 \%$ had a greater incidence of ARDS and early mortality than those with a perfusion fraction of $35 \%$ or less (Table 5). With that cut-off value, RRs of ARDS and early mortality for patients with a higher perfusion fraction were 5.57 (95\% CI, 1.54-20.2; $P=.009)$ and 3.84 (95\% CI, $1.34-11.05 ; P=.013)$, respectively.

\section{DISCUSSION}

In the present study we evaluated several predictors of postoperative ARDS and early mortality in the setting of a homogeneous series of patients subjected to pneumonectomy for lung cancer. The analyses on this homogeneous population have a significance in the respect that although most of the studies that analyzed the risk factors for pulmonary complications after lung resection included all types of 
TABLE 3. Univariable risk factor analyses for ARDS and early mortality

\begin{tabular}{|c|c|c|c|c|c|c|}
\hline & \multicolumn{3}{|c|}{ ARDS } & \multicolumn{3}{|c|}{ Early mortality } \\
\hline & $\mathbf{R R}$ & $95 \%$ CI & $P$ value & $\mathbf{R R}$ & $95 \%$ CI & $P$ value \\
\hline Age & 1.02 & $0.97-1.08$ & .487 & 1.04 & $0.98-1.09$ & .174 \\
\hline Sex & $\mathrm{NA}^{*}$ & $\mathrm{NA}^{*}$ & $>.999$ & $\mathrm{NA}^{*}$ & $\mathrm{NA}^{*}$ & .999 \\
\hline Diabetes mellitus & 2.38 & $0.30-18.95$ & .414 & 1.87 & $0.56-6.24$ & .310 \\
\hline Smoking & $\mathrm{NA} \dagger$ & $\mathrm{NA} \dagger$ & .998 & 2.34 & $0.29-18.7$ & .422 \\
\hline FVC & 1.02 & $0.98-1.05$ & .340 & 1.02 & $0.99-1.05$ & .133 \\
\hline $\mathrm{FEV}_{1}$ & 1.01 & $0.98-1.04$ & .530 & 1.01 & $0.99-1.04$ & .390 \\
\hline DLCO & 1.00 & $0.97-1.03$ & .975 & 1.00 & $0.98-1.03$ & .800 \\
\hline $\begin{array}{l}\text { Perfusion fraction } \\
\text { of resected lung }\end{array}$ & 1.10 & $1.03-1.17$ & $.003 \ddagger$ & 1.09 & $1.03-1.15$ & $.002 \ddagger$ \\
\hline ppo-FEV $1(\%)$ & 0.92 & $0.88-0.98$ & $.006 \ddagger$ & 0.93 & $0.89-0.98$ & $.005 \ddagger$ \\
\hline Neoadjuvant therapy & 1.25 & $0.36-4.35$ & .724 & 1.57 & $0.32-7.80$ & .583 \\
\hline Right (vs left) & 4.80 & $1.60-14.39$ & $.005 \ddagger$ & 4.09 & $1.54-10.80$ & $.005 \ddagger$ \\
\hline
\end{tabular}

pneumonectomy

$A R D S$, Acute respiratory distress syndrome; $R R$, relative risk; $C I$, confidence interval; $N A$, not applicable; $F V C$, forced vital capacity; $F E V_{l}$, forced expiratory volume in 1 second; $D L C O$, diffusion capacity of carbon monoxide; ppo- $F E V_{l}$, predicted postoperative forced expiratory volume in 1 second. *Incidences of events was 0 in female patients. $\dagger$ Incidence of ARDS was 0 in nonsmokers. $\ddagger P<.05$.

pulmonary resections, such as wedge resections, lobectomies, and pneumonectomies, ${ }^{2-4,11,12}$ only limited reports focused on pneumonectomy. ${ }^{7,8,13}$

Preoperative pulmonary function tests have been extensively performed to predict morbidity and mortality after pulmonary resection, with controversial results. Some investigators identified $\mathrm{FEV}_{1}$, forced vital capacity, or both as possible risk factors, ${ }^{3-5}$ but others could not find its association with postoperative complication. ${ }^{2,12,13}$ The importance of ppo-FEV $\mathrm{F}_{1}$ in predicting pulmonary complications and mortality after lung resection has been suggested in many studies. $^{2,5,6}$ Data from multivariable analyses indicated that ppo- $\mathrm{FEV}_{1}$ was an independent risk factor for operative mortality. ${ }^{2}$ A ppo- $\mathrm{FEV}_{1}$ of greater than $0.80 \mathrm{~L} / \mathrm{s}$ was determined as the cut-off point to allow minimal tissue oxygenation and cardiac output after lung resection. ${ }^{14}$ Subsequently, these values were widely accepted as the functional limit to perform pneumonectomy. Other authors advocate the use of ppo-FEV ${ }_{1}$, expressed as percent predicted, as a more accurate factor to predict pulmonary complications after lung resection, with $30 \%$ or $40 \%$ as the suggested limit. ${ }^{5,6}$ The

TABLE 4. Multivariable risk factor analyses for ARDS and early mortality

\begin{tabular}{|c|c|c|c|}
\hline & $\mathbf{R R}$ & $95 \%$ CI & $P$ value \\
\hline \multicolumn{4}{|l|}{ ARDS } \\
\hline $\begin{array}{l}\text { Perfusion fraction } \\
\text { of resected lung }\end{array}$ & 1.10 & $1.03-1.17$ & $.003^{*}$ \\
\hline ppo-FEV $1(\%)$ & 0.93 & $0.88-0.99$ & $.020^{*}$ \\
\hline \multicolumn{4}{|l|}{ Early mortality } \\
\hline $\begin{array}{l}\text { Perfusion fraction } \\
\text { of resected lung }\end{array}$ & 1.09 & $1.03-1.15$ & $.002 *$ \\
\hline ppo-FEV ${ }_{1}(\%)$ & 0.94 & $0.90-0.99$ & $.027 *$ \\
\hline
\end{tabular}

British Thoracic Society presented a widely used formulized set of recommendations involving a preoperative simple pul-

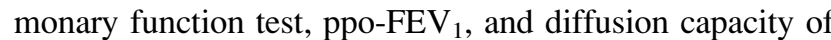
carbon monoxide for the preoperative assessment of surgical risk. $^{15}$

However, the ppo-FEV $\mathrm{Fe}_{1}$ as a predictor of pulmonary complication is currently a subject of controversy. In a study that analyzed 146 patients subjected to pneumonectomy, ${ }^{7}$ univariable analysis showed a significant association of ppo-FEV ${ }_{1}$ with pulmonary complications, but multivariable analysis revealed that the independent and significant factors affecting pulmonary complications were prior radiotherapy, perfusion of the remaining lung of $55 \%$ or less, and high intraoperative fluid load but not ppo- $\mathrm{FEV}_{1}$.

Although the preoperative risk factors assessed earlier mainly focused on ventilatory function parameters, hemodynamic factors have been also evaluated in several studies. ${ }^{7-10}$ It has been postulated that the adequacy of pulmonary vascular bed and circulation is more important than ventilatory capacity, influencing the postoperative exercise tolerance and gas exchange capacity. ${ }^{8,9}$ A study showed that high pulmonary artery pressure measured intraoperatively in patients undergoing pneumonectomy was associated with an increased incidence of cardiorespiratory complications and mortality. ${ }^{8}$ In another study pulmonary vascular resistance was

TABLE 5. Differences in ARDS incidence and early mortality according to the level of perfusion fraction of resected lung

Perfusion fraction

\begin{tabular}{lccc} 
of resected lung & No. of patients & ARDS, no. (\%) & Mortality, no. (\%) \\
\hline$>35 \%$ & 81 & $14(17.3)$ & $16(19.8)$ \\
$\leq 35 \%$ & 83 & $3(3.6)$ & $5(6.0)$ \\
$P$ value & & $.005^{*}$ & $.010^{*}$ \\
\hline
\end{tabular}

ARDS, Acute respiratory distress syndrome. $* P<.05$. 
measured by using right heart catheterization at rest and during exercise. ${ }^{9}$ The group observed that high pulmonary vascular resistance was a better predictor of mortality than simple pulmonary function tests. These results have been interpreted as a consequence of secondary pulmonary hypertension caused by a reduction in the pulmonary capillary bed.

A group investigated the predictive value of several preoperative factors on the intraoperative course during single-lung ventilation for lung resection. The cited study revealed that a preoperative low $\mathrm{PaO}_{2}$ value during exercise and low perfusion fraction of nonresected lung were independent risk factors influencing the decrease in the $\mathrm{PaO}_{2} /$ fraction of inspired oxygen ratio during intraoperative single-lung ventilation. ${ }^{10}$ The authors concluded that preoperative $\mathrm{PaO}_{2}$ values during exercise and lung perfusion scan data were useful in identifying patients at high risk of abnormal gas exchange during lung resection surgery. These findings provide insight into the postpneumonectomy clinical setting, suggesting that the preoperative distribution of lung perfusion might be predictive of the gas exchange capacity and thus postoperative pulmonary complications in patients undergoing pneumonectomy.

In the present study ARDS occurred in $17(10.4 \%)$ patients, resulting in 15 deaths. The perfusion level of the resected lung was a significant predictor for postoperative

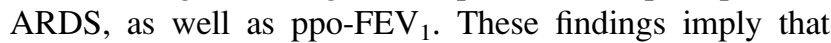
hemodynamic factors of pulmonary circulation can be as important as conventional ventilatory parameters in the development of postoperative ARDS.

In our study right pneumonectomy was not related to an increased incidence of ARDS and early mortality compared with left pneumonectomy. Whereas several studies reported that right-sided pneumonectomy resulted in a greater incidence of pulmonary complications, ${ }^{3,16}$ another group maintained that the side of resection was not associated with pulmonary complications. ${ }^{7}$ The latter group insisted that removal of a lung regardless of right or left side, normally perfused and functioning, results in a dramatic increase in blood flow and fluid filtration in the remaining lung. This hypothesis is supported by an experimental study that showed that tissue fluid filtration increases with blood overflow, resulting in pulmonary parenchymal edema. ${ }^{17}$ Therefore quantitative analysis of the amount of perfusion in both lungs appears to have better predictive value than the side of pneumonectomy in the prediction of pulmonary edema and ARDS.

\section{Limitation}

This study is subject to limitations inherent to retrospective observational studies.

Because 164 (39\%) of 425 patients undergoing simple pneumonectomy who underwent preoperative lung perfusion scanning were included in the present study, the study results might not be generalizable to all patients undergoing pneumonectomy. Candidates for lung resection for lung cancer were evaluated according to the institution's standardized and stratified protocols; therefore selection bias in the performance of lung perfusion scanning was minimal. Consequently, the subject population represented high-risk patients, as evidenced by more frequent smoking history and poorer pulmonary function test results. In terms of operative outcomes, patients who underwent preoperative lung perfusion scanning had a greater incidence of ARDS (17/ $164[10.4 \%]$ vs $15 / 261[5.7 \%], P=.079)$ and early mortality $(21 / 164[12.8 \%]$ vs $17 / 261[6.5 \%], P=.027)$ than those who did not. These findings also support the idea that the patients included in this study had greater surgical risks than the average patient undergoing pneumonectomy. A further study involving preoperative lung perfusion scan evaluation in all patients is needed to verify the results of the present study.

\section{CONCLUSIONS}

ARDS is the major cause of mortality after pneumonectomy for lung cancer, and patients with a low ppo-FEV ${ }_{1}$ or a high perfusion fraction of resected lung display higher rates of postoperative ARDS and mortality. Therefore even though the ppo-FEV ${ }_{1}$ appears to be within acceptable limits for pneumonectomy, more attention should be given to patients with a higher perfusion fraction of resected lung.

\section{References}

1. Bernard GR, Artigas A, Brigham KL, Carlet J, Falke K, Hudson L, et al. The American-European Consensus Conference on ARDS. Definitions, mechanisms, relevant outcomes, and clinical trial coordination. Am J Respir Crit Care Med. 1994;149:818-24

2. Kearney DJ, Lee TH, Reilly JJ, DeCamp MM, Sugarbaker DJ. Assessment of operative risk in patients undergoing lung resection. Importance of predicted pulmonary function. Chest. 1994;105:753-9.

3. Patel RL, Townsend ER, Fountain SW. Elective pneumonectomy: factors associated with morbidity and operative mortality. Ann Thorac Surg. 1992;54:84-8.

4. Dales RE, Dionne G, Leech JA, Lunau M, Schweitzer I. Preoperative prediction of pulmonary complications following thoracic surgery. Chest. 1993;104:155-9.

5. Wahi R, McMurtrey MJ, DeCaro LF, Mountain CF, Ali MK, Smith TL, et al. Determinants of perioperative morbidity and mortality after pneumonectomy. Ann Thorac Surg. 1989;48:33-7.

6. Markos J, Mullan BP, Hillman DR, Musk AW, Antico VF, Lovegrove FT, et al. Preoperative assessment as a predictor of mortality and morbidity after lung resection. Am Rev Respir Dis. 1989;139:902-10.

7. Parquin F, Marchal M, Mehiri S, Herve P, Lescot B. Post-pneumonectomy pulmonary edema: analysis and risk factors. Eur J Cardiothorac Surg. 1996;10: 929-33.

8. Rams JJ, Harrison RW, Fry WA, Moulder PV, Adams WE. Operative pulmonary artery pressure measurements as a guide to postoperative management and prognosis following pneumonectomy. Dis Chest. 1962;41:85-90.

9. Fee HJ, Holmes EC, Gewirtz HS, Ramming KP, Alexander JM. Role of pulmonary vascular resistance measurements in preoperative evaluation of candidates for pulmonary resection. J Thorac Cardiovasc Surg. 1978;75:519-24.

10. Ribas J, Jimenez MJ, Barbera JA, Roca J, Gomar C, Canalis E, et al. Gas exchange and pulmonary hemodynamics during lung resection in patients at increased risk: relationship with preoperative exercise testing. Chest. 2001;120:852-9.

11. Stephan F, Boucheseiche S, Hollande J, Flahault A, Cheffi A, Bazelly B, et al. Pulmonary complications following lung resection: a comprehensive analysis of incidence and possible risk factors. Chest. 2000;118:1263-70. 
12. Busch E, Verazin G, Antkowiak JG, Driscoll D, Takita H. Pulmonary complications in patients undergoing thoracotomy for lung carcinoma. Chest. 1994;105:760-6.

13. Harpole DH, Liptay MJ, DeCamp MM Jr, Mentzer SJ, Swanson SJ, Sugarbaker DJ. Prospective analysis of pneumonectomy: risk factors for major morbidity and cardiac dysrhythmias. Ann Thorac Surg. 1996;61:977-82.

14. Block AJ, Olsen GN. Preoperative pulmonary function testing. JAMA. 1976;235: 257-8.
15. BTS guidelines. guidelines on the selection of patients with lung cancer for surgery. Thorax. 2001;56:89-108.

16. Turnage WS, Lunn JJ. Postpneumonectomy pulmonary edema. A retrospective analysis of associated variables. Chest. 1993;103:1646-50.

17. Nakahara K, Nanjo S, Matsumura A, Kawashima Y. Effect of pulmonary blood flow on lung water and pulmonary hemodynamics in the canine lung lobe. Eur Surg Res. 1990;22:136-42.

Access to The Journal of Thoracic and Cardiovascular Surgery Online is reserved for print subscribers!

Full-text access to The Journal of Thoracic and Cardiovascular Surgery Online is available for all print subscribers. To activate your individual online subscription, please visit The Journal of Thoracic and Cardiovascular Surgery Online, point your browser to http://www.mosby.com/itcvs, follow the prompts to activate your online access, and follow the instructions. To activate your account, you will need your subscriber account number, which you can find on your mailing label (note: the number of digits in your subscriber account number varies from 6 to 10 ). See the example below in which the subscriber account number has been circled:

\section{Sample mailing label}

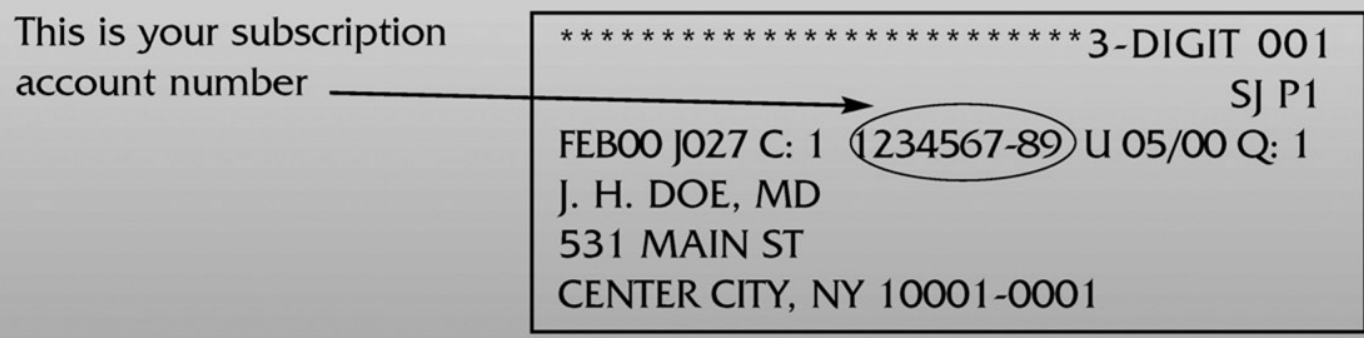

Personal subscriptions to The Journal of Thoracic and Cardiovascular Surgery Online are for individual use only and may not be transferred. Use of The Journal of Thoracic and Cardiovascular Surgery Online is subject to agreement to the terms and conditions as indicated online. 